は不純物として，PTMC を若干含えでおり，その面積 比から含有量は 0.8〜 1.0\%であった。これは，本法に よる MTMC の分析值と TLC-UV 法による值との差 にほぼ等しく，本法では PTMC に影響なく $\mathrm{MTMG}$ を分析することができた。

\section{4 結馬}

MTMG の分析法として，TLGで $m$-クレゾールなど の不純物を分離除去し, エタノールで抽出して加水分 解したのち, pH 8.3 で, 4-アミノアンチピリンで発色 し, 比色定量する方法を確立した. 一方, 工業用 MTMC のカーバメート組成を TLG 処理後, 加水分解して, クレゾールの GG により分析した結果, 不純物として PTMC】を 0.8〜1.0\% 含有していることを確認した. 本法による分析值は，さきに報告した TLG-UV 法によ る值よりも約 $1 \%$ 低くなり，それは，4-アミノアンチピ リンで発色しない PTMCが, TLC-UV 法では MTMC として分析されるためであり,本法により不純物 PTMC に影響なく，正磪に MTMC を分析することができた。

本研究の発表を許可された当社の上司のかたがた, ご 助言をいただいた本郷英太郎研究共通部長代理に厚くお 礼申し上げます。

\section{交献}

1) F. D. Snell, C. T. Snell : "Colorimetric Methods of Analysis", 3rd Ed., Vol. III, p.
116 (1953).

2) R. W. Martin : Anal. Chem., 21, 1419 (1949).

3) 鈴木照麿監修: “農薬公定検査法註解”, p. 101 (1967), (南江堂).

4) J. Kolšek, M. Matičič : J. Chromatog., 12, 305 (1963).

$$
\dot{s}
$$

Colorimetric determination of 3-methylphenyl $\boldsymbol{N}$-methylcarbamate with 4-aminoantipyrine. (Analytical studies on pesticides and related compounds. II.) Atsushi Murano (Osaka Works, Sumitomo Chemical Co. Ltd., Konohana-ku, Osaka-shi)

A colorimetric method has been developed for the determination of 3-methylphenyl $N$-methylcarbamate (MTMG). The MTMG was separated from impurities by thin layer chromatography (TLC), eluted with ethanol and hydrolyzed with potassium hydroxide. After color development with 4-aminoantipyrine and potassium ferricyanide at pH 8.3, MTMG was spectrophotometrically determined by its absorbance at 495 $\mathrm{m} \mu$. Results of the analysis of several samples of technical MTMG were about 1\% lower than those obtained by thin layer chromatographic separation and spectrophotometric method already reported. On the other hand, the gas chromatographic determination of 4-methylphenyl $N$-methylcarbamate(PTMG) which was not separated from MTMG by TLG and of which color was not developed with 4-aminoantipyrine indicated that its content in MTMG was about $1 \%$ just in accordance with the difference between the value by two methods. The MTMG was thus determined without the interference from PTMC by the proposed method.

(Received Feb. 9, 1970)

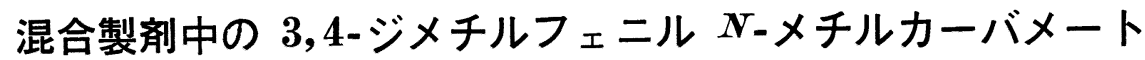 および 3-メチルフェニル $N$-メチルカーバメートの定量*
}

\author{
村 野 敦**
}

(1970 年 2 月 9 日受理)

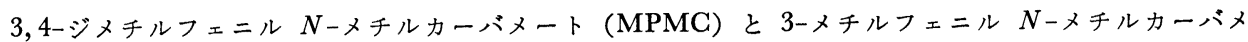
一ト (MTMG) とを有効成分とする混合製剤中の両者の分析法を確立した。前処理として, 薄層ク口 マトグラフィー (TLC) で不純物を分離除去したのち，カーバメートをエタノールで抽出し，水酸化 カリウム溶液を加えて加水分解し, 紫外部の吸収スペクトルを測定して, MTMG と MPMC の等吸 収点である波長 $296.5 \mathrm{~m} \mu$ における吸光度を測定して, 全カーバメートを定量する。一方, 4-フミノフ ンチピリンによって, MTMCを比色定量して, 両者の值の差から, MPMG を定量する.
\end{abstract}

*農薬および関連化合物の分析に関する研究 (第 3 報). 第 2 報は村野 敦：本誌, 19, 1074 (1970)

** 住友化学工業(株)大阪製造所研究共通部 : 大阪市此花区春日出町 


\section{1 緒言}

MPMC および MTMC 池のフェニル N-メチルカ 一バメートと同様に，ウンカ，ヨコバイ類の殺虫郕とし て広く使用されている。

すでに，MPMC の分析法として，TLGにより不純 物を分離除去し，メタノールで抽出後，アルカリ性で加 水分解して紫外部の吸収スペクトルを測定し，その極大 波長の吸光度から 定量する方法1)（TLC-UV 法）を， また，MTMG の分析法として，TLC-UV 法1および アミノアンチピリンによる比色定量法2を報告した。

MPMC および MTMC 混合製剤中の両成分の分析法 として，MPMCが 4-アミノアンチピリンで発色しな いことを利用して，比色法で MTMC を定量し，また， TLC-UV 法で全カーバメートを定量し，両者の值の差 から MPMC 含量を求める方法を， $2 \%$ 混合粉片につ いて検討し，満足すべき結果を得たので報告する.

\section{2 実験および考察}

\section{1 試薬，器具および装置}

MPMC 標準品：既報1による. mp 79 80 ${ }^{\circ} \mathrm{C}$. MTMC 標準品：既報1による. $\mathrm{mp} 74.5 \sim 76^{\circ} \mathrm{C}$. 水酸化カリウム溶液: 水酸化カリウム $65 \mathrm{~g}$ に水を加 えて溶かし $1000 \mathrm{ml}$ とする.

リン酸二水素カリウム溶液：リン酸二水素カリウム $45.36 \mathrm{~g}$ に水を加えて溶かし $1000 \mathrm{ml}$ とする.

水酸化ナトリウム溶夜: 水酸化ナトリウム $13.5 \mathrm{~g}$ に 水を加えて $1000 \mathrm{ml}$ として原液とする。原液 $50 \mathrm{ml}$ に リン酸二水素カリウム溶液 $50 \mathrm{~m} l$ を加えてよく振り混ぜ て $\mathrm{pH}$ を測定するとき， $\mathrm{pH}$ が 8.3 になるように，原 液を希釈して調製する。

4-アミノアンチピリン溶液：4-アミノアンチピリン $1 \mathrm{~g}$ に水を加えて溶かし $100 \mathrm{ml}$ とする。

フェリシアン化カリウム溶液：フェリシアン化カリウ ム $2.5 \mathrm{~g}$ に水を加えて溶かし $100 \mathrm{ml}$ とする.

その他の試薬 : JIS 試薬特級.

薄層プレート: シリカゲル $\mathrm{HF}_{254}$ (Merck), 厚さ 0.5 $\mathrm{mm}$ ，大きさ $20 \times 20 \mathrm{~cm}$.

ガラスろ過器 : JIS R 3503 の 3G-4.

展開そう: 縦 $11 \mathrm{~cm}$, 横 $22 \mathrm{~cm}$, 高さ $22 \mathrm{~cm}$.

紫外線ランプ: 東芝 F1-3S 型.

島津 SV-50 型自記分光光度計.

\section{2 薄層クロマトグラフィー}

展開溶媒として， $n$-ヘキサン+酢酸エチル十ギ酸 $(80$ : $20: 1)$ を用いると，MPMC および MTMC は不純

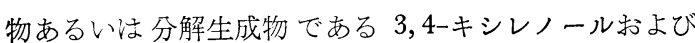
m-クレゾールとは分離するが，MPMG と MTMC は 互いに分離しない。

\section{3 全カーバメートの定量法の検討}

溶媒として， $0.2 N$ 水酸化カリウ $\Delta の 80 \%$ エタ 一ル溶液を用いて，MPMC および MTMC の紫外部 吸収 スペクトルを測定すると，Fig. 1 に示すように， MPMC 波長 $297 \mathrm{~m} \mu$ に, MTMC は波長 $292 \mathrm{~m} \mu$ に それぞれ極大吸収を，また，波長 $296.5 \mathrm{~m} \mu$ に等吸収点 を有するので，等吸収点を利用して，全カーバメートを 定量した。

検量線は，Fig. 2 に示すように，いずれも濃度 20〜 $50 \mu \mathrm{g} / \mathrm{m} l$ の範囲で原点を通る直線となった．定量用標 準品には，極大波長が等吸収点に近い MPMC を用い た。なお，薄層ブランクの影響を除去するために，既 報1) と同様にして，296.5 m $\mu$ における吸光度から 330 $\mathrm{m} \mu$ における吸光度を隇じて，カーバメートの吸光度と

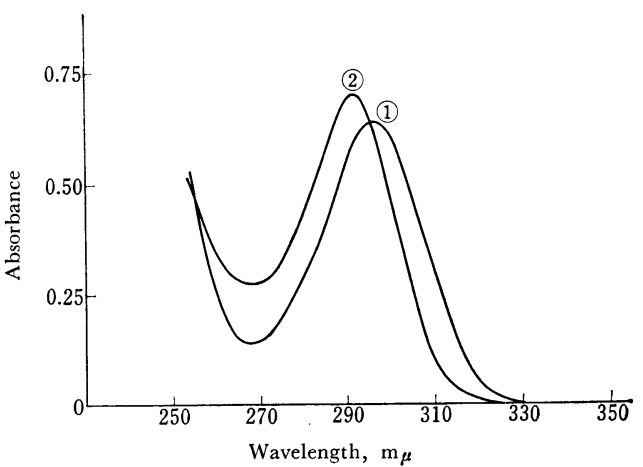

Fig. 1 Absorption spectra of MPMC and MTMC Concentration : $40 \mu \mathrm{g} / \mathrm{ml}$; Solvent : $0.2 N$ ethanolic potassium hydroxide solution; (1) MPMC; (2) MTMC

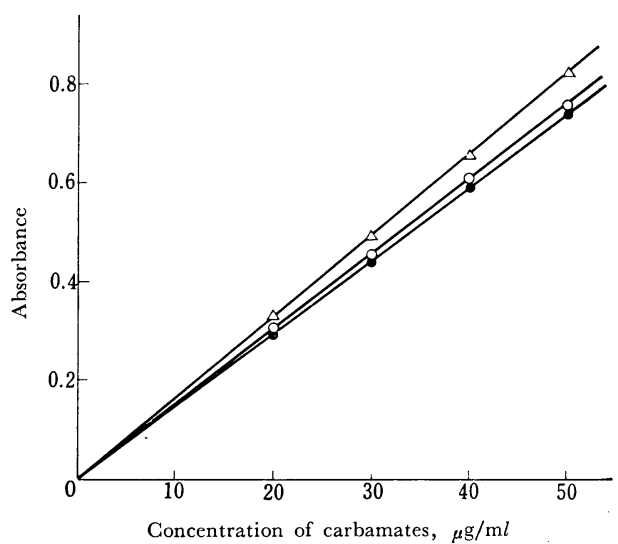

Fig. 2 Calibration curve for total carbamates - - MPMC and MTMC at $296.5 \mathrm{~m} \mu$ (isobestic point); -O-MPMC at $297 \mathrm{~m} \mu ;-\triangle-$ MTMC at $292 \mathrm{~m} \mu$ 
した。

\subsection{MTMG の定量法の検討}

すでに報告2)したように，4-アミノアンチピリンによ り, MTMG は赤とう色に発色するが，MPMC は発色 しないので，MPMCの存在下で MTMCの発色条件を 検討した．前報2の条件では，MPMC がわずかに濁り を生じ, Table I に示すように, MTMC の定量の妨げ となるが，エタノール濃度を増すと徐々に影響はなくな り，エタノール濃度 20\% では，MPMC の影響はほと んどなくなった。また，エタノールの濃度を増すと， MTMC の吸収スペクトルの極大波長は短波長側にず れ，20\% エタノール溶液中での 極大波長は $483 \mathrm{~m} \mu$ で あった。

Table I Effect of ethanol on absorbance

\begin{tabular}{cccc}
\hline $\begin{array}{c}\text { Concentration of } \\
\text { ethanol }(\%)\end{array}$ & MPMG & Absorbance \\
\cline { 2 - 4 } & MTMG & $\begin{array}{c}\text { MPMC }+ \\
\text { MTMC }\end{array}$ \\
\hline 8 & 0.022 & - & - \\
16 & 0.008 & 0.576 & 0.590 \\
20 & 0.004 & 0.608 & 0.610 \\
24 & 0.004 & 0.620 & 0.619 \\
\hline
\end{tabular}

検量線注, MTMC 濃度 $2 \sim 10 \mu \mathrm{g} / \mathrm{ml}$ の範囲で原点 を通る直線となった. 定量濃度は $8 \mu \mathrm{g} / \mathrm{ml}$ である.

\section{5 分析操作法}

2.5 .1 全カーバメートの分析 カーバメートとして 約 $125 \mathrm{mg}$ に相当する試料它精密に量り $\left(W_{t} \mathrm{mg}\right)$, ク ロロホルム $25 \mathrm{~m} l$ 它正確に加えて 20 分間振とう抽出 する.上澄液 $1 \mathrm{ml}$ をホールピペットを用いて正確にと り，薄層プレートの下端から約 $2 \mathrm{~cm}$ の位置に，両端約 $2 \mathrm{~cm}$ を残して点線状に添付し, ピペットの先端は外側 から少量のクロロホルムで洗い, 洗液も合わせて添付す る。薄層プレートは, 溶媒を除いたのち展開そうに入 れ，nーヘキサン: 酰酸エチル : ギ酸 $(80: 20: 1)$ を展 開溶媒として, 上昇法で約 $13 \mathrm{~cm}$ 展開する. 展開後, 薄 層プレートに冷風を送って溶媒を除き，紫外線ランプを 照射して，カーバメートに相当する部分 $\left(R_{f}\right.$ 值約 0.25$)$ を確認する・カーバメートに相当する部分のシリカゲル を, 先端の平らなへらを用いてかき取り, ガラスろ過器 に入れる. エタノール $5 \mathrm{ml}$ ずつで 4 回抽出して吸引ろ 過し, 抽出した液を集めて, エタノ一ルを加えて正確に $25 \mathrm{ml}$ とし，抽出液とする.

抽出液の $10 \mathrm{ml}$ を正確にとり, 水酸化カリウム溶液
$10 \mathrm{ml}$ およびエタノールを加えて正確に $50 \mathrm{ml}$ とし, 試 料溶液とする.

別に, MPMC 標準品約 $125 \mathrm{mg}$ を精密に量り（ $W_{\mathcal{S}}$ $\mathrm{mg}$ ), エタノールを加えて溶かし正確に $25 \mathrm{ml}$ とする. この液の $1 \mathrm{ml}$ をホールピペットを用いて正確にとり, エタノールを加えて正確に $25 \mathrm{ml}$ とする. この液の 10 $\mathrm{m} l$ を正確にとり，水酸化力リウム溶液 $10 \mathrm{~m} l$ および エタノールを加えて正確に $50 \mathrm{ml}$ とし，標準溶液とす る.

試料溶液および標準溶液につき, 水酸化カリウム溶液 $10 \mathrm{~m} l$ にエタノールを加えて正確に $50 \mathrm{~m} l$ とした液を対 照液として, 層長 $10 \mathrm{~mm}$ で, 波長 $296.5 \mathrm{~m} \mu$ および $330 \mathrm{~m} \mu$ における吸光度 $E_{t}, E_{s}$ および $E_{t}{ }^{\prime}, E_{s}{ }^{\prime}$ を測 定し, 次式によって, 全カーバメート（\%)を算出す る.

$$
\text { 全カーバメート }(\%)=\frac{W_{s}}{W_{t}} \times \frac{E_{t}-E_{t}^{\prime}}{E_{s}-E_{s}{ }^{\prime}} \times 100
$$

2.5.2 MTMCの分析 $2 \cdot 5 \cdot 1$ で得た抽出液の $4 \mathrm{ml}$ を正確に量り, 水酸化ナトリウム溶液 $5 \mathrm{ml}$ を正確に加 えてよく混合し, 室温に 5 分間放置する. リン酸二水素 カリウム溶液 $5 \mathrm{ml}$ を正確に加えて $\mathrm{pH} 8.3$ とし，4アミノアンチピリン溶液 $1 \mathrm{ml}$, フェリシアン化カリウ ム溶液 $1 \mathrm{ml}$, エタノール $6 \mathrm{ml}$ および 水を加えて正確 に $50 \mathrm{ml}$ とし, 試料溶液とする.

別に, MTMC 標準品約 $125 \mathrm{mg}$ を精密に量り ( $W_{s}$ $\mathrm{mg}$ ，エタノールを加えて溶かし正確に $25 \mathrm{ml}$ とする. この液 $1 \mathrm{ml}$ をホールピペットを用いて正確にとり, エ タノールを加えて正確に $25 \mathrm{ml}$ とする. この液の $4 \mathrm{ml}$ を正確にとり, 以下試料溶液の場合と同様に操作して, 標準溶液とする.

さらに別に, エタノール $4 \mathrm{~m} l$ につき, 以下試料溶液 の場合と同様に操作して，ブランク溶液とする.

試料溶液および標準溶液につき, ブランク溶液を対照 液として, 層長 $10 \mathrm{~mm}$ で, 波長 $483 \mathrm{~m} \mu$ における吸光 度 $E_{t}$ および $E_{s}$ を測定し, 次の式によって MTMC （\%）を算出する.

$$
\operatorname{MTMG}(\%)=\frac{W_{s}}{W_{t}} \times \frac{E_{t}}{E_{s}} \times 100
$$

\subsubsection{MPMC の分析 次式によって, MPMC}

（\%）を算出する.

$$
\begin{aligned}
\operatorname{MPMG}(\%)= & \text { 全カーバメート（\%) } \\
& -\operatorname{MTMG}(\%)
\end{aligned}
$$


Table II Analysis of mixed dust formulations containing MPMC and MTMC

\begin{tabular}{|c|c|c|c|c|c|c|c|c|c|}
\hline & \multicolumn{3}{|c|}{ Total carbamates } & \multicolumn{3}{|c|}{ MTMG } & \multicolumn{3}{|c|}{ MPMC } \\
\hline & $\begin{array}{c}\text { Added } \\
(\%)\end{array}$ & $\begin{array}{c}\text { Found } \\
(\%)\end{array}$ & $\begin{array}{l}\text { Recovery } \\
(\%)\end{array}$ & $\begin{array}{l}\text { Added } \\
(\%)\end{array}$ & $\begin{array}{c}\text { Found } \\
(\%)\end{array}$ & $\begin{array}{c}\text { Recovery } \\
(\%)\end{array}$ & $\begin{array}{l}\text { Added } \\
(\%)\end{array}$ & $\begin{array}{c}\text { Found } \\
(\%)\end{array}$ & $\begin{array}{c}\text { Recovery } \\
(\%)\end{array}$ \\
\hline \multirow[t]{5}{*}{ Synthetic } & 2.01 & 2.00 & 99.6 & 1.00 & 1.01 & 101.0 & 1.01 & 0.99 & 98.0 \\
\hline & & 2.02 & 100.5 & & 1.00 & 100.0 & & 1.02 & 101.0 \\
\hline & & 2.02 & 100.5 & & 1.00 & 100.0 & & 1.02 & 101.0 \\
\hline & & 2.01 & 100.0 & & 1.00 & 100.0 & & 1.01 & 100.0 \\
\hline & & 2.03 & 101.0 & & 1.01 & 101.0 & & 1.02 & 101.0 \\
\hline \multirow[t]{3}{*}{ Unknown } & & 2.08 & & & 1.01 & & & 1.07 & \\
\hline & & 2.04 & & & 1.01 & & & 1.03 & \\
\hline & & 2.03 & & & 1.01 & & & 1.02 & \\
\hline
\end{tabular}

\section{6 分析結果}

粉剤の標準混合試料 (MPMG $1 \%+$ MTMG $1 \%$ ) および未知試料の分析結果を Table II に示す. 分析值 の再現性もよく, 標準混合試料の回収率注定量的であ り，正確に分析することができた。

\section{3 結言}

混合製戍から MPMC および MTMC をクロロホル ムで抽出し，TLC で不純物を分離除去したのち，加水 分解して, 等吸収点 $296.5 \mathrm{~m} \mu$ の吸光度から全カーバメ 一トを定量し，4-アミノアンチピリンによる比色法で MTMC を定量し，両分析值の差から MPMC を定量 した・本法によれば不純物として含まれる $m$ ークレン゙ー ルや 3,4-キシレノールなどの影響を受けることなく MPMC および MTMC を定量することができた.

本研究の発表を許可された当社の上司のかたがた，ご 助言をいただいた本郷英太郎研究共通部長代理に深謝し ます。

\section{交献}

1) 村野 敦：本誌，19，946 (1970).
2) 村野 敦: 同上, 19, 1074 (1970).

$$
\text { is }
$$

Determination of 3,4-dimethylphenyl $N$-methylcarbamate and 3-methylphenyl $N$-methylcarbamate in mixed formulations. (Analytical studies on pesticides and related compounds. III.) Atsushi Murano (Osaka Works, Sumitomo Chemical Co. Ltd., Konohana-ku, Osaka-shi)

A quantitative analytical method has been developed for the determination of 3,4-dimethylphenyl $N$-methylcarbamate (MPMC) and 3-methylphenyl $N$-methylcarbamate (MTMC) in mixed formulations. Both MPMC and MTMC were extracted with chloroform, separated from impurities by thin layer chromatography, eluted with ethanol and hydrolyzed with potassium hydroxide solution. Total carbamate content was determined by measuring the absorbance at $296.5 \mathrm{~m} \mu$, which was an isobestic point of MPMC and MTMC. On the other hand, MTMC was determined colorimetrically after the reaction with 4-aminoantipyrine at $\mathrm{pH}$ 8.3, and MPMC was determined from the difference between total carbamate content and MTMC content. The analysis of a dust formulation indicated that the proposed method gave precise and reproducible results.

(Received Feb. 9, 1970) 